\title{
GRADING IN AGRICULTURAL JUDGING CONTESTS
}

\author{
By L. J. Briggs, U. S. Department of Agriculture.
}

An interesting and valuable feature of modern agricultural education is the development of competitive contests among students in judging and arranging in order of merit agricultural products submitted for examination. Thus, for example, the test may be to determine who can arrange a certain group of 5 ears of corn most nearly in order of excellence, the best ear, let us say, to be placed at the left. : Since there are 120 permutations possible in the arrangement of the 5 ears of corn, the judges soon become hopelessly involved in complications unless some definite system of grading is adopted. President E: R:Nichols of the Kansas Agricultural College, appreciating this difficulty;, has suggested a system of grading in which the penalty to be imposed: for misplacing an ear is arbitrarily made much greater for the best ear than for the poorest. This plan does not seem to me strictly: logical when applied to a general scheme of grading, since we; have no reason for assuming that the best individuals can be more readilydetected than the poorest. Furthermore, from a practical standpoint, it is quite as important for the student to recognize the deficiencies of a poor ear of corn as to appreciate the points of excellence in a good-one. The plan suggested by President Nichols also gives rise to a rather complicated system of grading, necessitating the use of tables to determine the grade corresponding to any given arrangement; and, finally, it is not free from the ban of empiricism.

I have, therefore, ventured to call attention to the following system. of preparing grading tables in which the difficulties mentioned above are avoided. This system can perhaps be most readily explained by referring again to a concrete case. Thus, if we assume that the error committed by exchanging the relative positions of the two poorest ears of corn is no greater than that resulting from changing the relative positions of the two best ears-or, in other words, if an error of displacement counts the same, no matter where it occurs-then the 120 permutations possible in the case of the 5 ears fall into 11 classes, and the grading becomes much simplified. To make the matter clearer, let us designate the 5 ears of corn by the numerals $1,2,3,4,5$, arranged in order of excellence, No. 1, the best ear, being at the left. We assume then that the error committed by the student in arranging the ears $2,1,3,4,5$ is no greater than in case of the arrangement $1,2,3, .5,4$, or $1,2,4,3,5$, or any similar arrangement in which a single displacement occurs. Without specific knowledge of the individual characteristics of the objects to be arranged this assumption is the only logical one.

On the above basis, the complete failure of the student would be represented by the arrangement $5,4,3,2,1$. In order to change the objects from this arrangement into the correct positions it is evident that the following displacements will be necessary: 


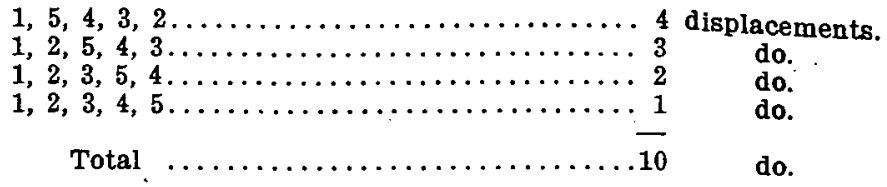

By a displacement is here meant the interchanging of the positions of two adjacent objects. Thus in order to transfer No. 1 into its correct place from the arrangement $5,4,3,2,1$, it is necessary to interchange it first with 2 , then with 3 , then with 4 , and finally with 5 , thus requiring four displacements, resulting in the arrangement $1,5,4,3,2$. In order to get No. 2 into its proper place, it is evident that three displacements are necessary, and so on, requiring altogether 10 displacements, starting with the worst possible arrangement, in order to bring the objects into their proper sequence.

Therefore, since the greatest possible number of displacements is 10 in the case of 5 objects, if we grade the correct arrangement as 100 and the complete failure as zero, all other possible arrangements must fall into some one of the 9 intermediate classes and may, therefore, be graded as 90 per cent, 80 per cent, 70 per cent, etc., according to the number of displacemnts necessary to bring the objects into the correct arrangement. The following examples will serve to illustrate this :

$2,1,3,4,5 \ldots \ldots \ldots \ldots 1$ displacement $\ldots \ldots \ldots \ldots 90$ per cent.

$2,3,1,4,5 \ldots \ldots \ldots \ldots 2$ displacements.........80 per cent.

$1,3,4,5,2 \ldots \ldots \ldots \ldots .3$ displacements..........70 per cent.

$3,4,2,5,1 \ldots \ldots \ldots, 6$ displacements. . . . . . 40 per cent.

A little practice enables the correct grade to be determined simply by inspection. If tables are desired, they can, however, be very quickly calculated and possess a symmetry whereby checking is made easy.

As the number of objects in the group increases, the number of permutations or possible arrangements increases at an enormous rate, making some definite system of grading a necessity. This is well illustrated in the following table, in which the total number of permutations or arrangements possible for different groups of objects up to 10 is given, together with the maximum number of displacements necessary to bring each group into a correct arrangement, and the corresponding percentage value of each displacement.

\begin{tabular}{|c|c|c|c|}
\hline $\begin{array}{l}\text { Number of } \\
\text { objects in } \\
\text { group. }\end{array}$ & $\begin{array}{c}\text { Number of } \\
\text { possible } \\
\text { arrangements. }\end{array}$ & $\begin{array}{c}\text { Maximum } \\
\text { number of } \\
\text { displacements. }\end{array}$ & $\begin{array}{c}\text { Percentage } \\
\text { value of one } \\
\text { displacement. }\end{array}$ \\
\hline $\begin{array}{r}2 \\
3 \\
4 \\
5 \\
6 \\
5 \\
8 \\
9 \\
9 \\
10\end{array}$ & $\begin{array}{r}2 \\
6 \\
24 \\
120 \\
720 \\
5040 \\
40320 \\
362880 \\
3628800\end{array}$ & $\begin{array}{r}1 \\
3 \\
6 \\
10 \\
15 \\
21 \\
28 \\
34 \\
45\end{array}$ & $\begin{array}{r}100 . \\
33.3 \\
16.6 \\
10.0 \\
6.6 \\
4.7 \\
3.6 \\
2.8 \\
2.2\end{array}$ \\
\hline
\end{tabular}

